\title{
100 years of insulin: progress, current perspectives and future challenges
}

\author{
James Cantley ${ }^{101}$ and Decio Eizirik ${ }^{2}$ \\ 'School of Medicine, University of Dundee, Dundee, Scotland, UK \\ 2ULB Center for Diabetes Research, Medical Faculty, Université Libre De Bruxelles, Brussels, Belgium
}

Correspondence should be addressed to J Cantley: jcantley001@dundee.ac.uk

This editorial forms part of a special section on 100 years of insulin. The guest editors for this section were James Cantley and Decio Eizirik.

Insulin secretion from pancreatic beta cells is critical to regulate blood glucose levels and maintain nutrient homeostasis (Cantley \& Ashcroft 2015). Defects in insulin secretion and action lead to diabetes mellitus, a disease characterised by hyperglycaemia, an array of co-morbidities and increased mortality. During type 1 diabetes (T1D), beta cells are targeted by the immune system leading to a profound loss of insulin secretion. Type 2 diabetes (T2D) is the most prevalent form ( $\sim 90 \%$ of cases), involving alterations in both insulin secretion and insulin sensitivity (the effectiveness of insulin): some individuals show a severe loss of insulin secretion, whereas others show obesity, insulin resistance and hyperinsulinemia, albeit insufficient to control blood glucose. In both forms of diabetes, a relative or absolute beta-cell failure is the central event leading to hyperglycaemia (Eizirik et al. 2020).

Prior to the discovery of insulin, people with T1D suffered immeasurably, with uncontrolled hyperglycaemia eventually resulting in diabetic ketoacidosis and death. Desperate attempts to control the disease, such as the so-called 'starvation' diets (Allen et al. 1919), muchreduced quality of life yet were of limited efficacy. Against this backdrop, it is perhaps difficult to overstate the immediate and long-lasting impact that the discovery of insulin by Banting, Best, Collip and Macleod had on the clinical treatment of diabetes. Following the pioneering experiments conducted at the University of Toronto in 1921 (Banting \& Best 1922), translation was rapid, with the introduction of bovine insulin replacement therapy resulting in a dramatic improvement in life expectancy and quality of life for people with diabetes, setting the path towards the development of modern recombinant human insulin therapies in the latter 20th century.

Alongside the direct clinical impact of insulin replacement therapy, the discovery of insulin catalysed development of the nascent field of endocrinology, while enabling profound advances in our scientific understanding of disease aetiology. Although insulin replacement therapy has saved countless lives, turning a fatal disease into a treatable chronic one, it is important to remember that insulin replacement does not recapitulate the exquisitely nutrient-regulated insulin secretion profiles of the pancreatic beta cell. Moreover, insulin therapy introduces side effects such as weight gain and risk of hypoglycaemia, at least in part due to the need to 'hyperinsulinise' the peripheral tissues to reach physiological levels of the hormone in the portal system. Therefore, new diseasemodifying therapies to protect and restore beta-cell function are urgently needed (Martens et al. 2021). A final point to note at this important anniversary is the diverse backgrounds, training, personalities and modus operandi of Banting, Best, Collip and Macleod (Bliss 2007), providing useful lessons about the multidisciplinary path to scientific discovery, the need for collaboration, and the importance of taking on high-risk projects where others have fallen short. 
To celebrate 100 years since the discovery of insulin, the Journal of Endocrinology has commissioned a series of reviews, authored by scientists from around the globe, covering a range of perspectives on the pathophysiology of diabetes. These articles provide a timely review of the progress made over the past century, a discussion of the latest research, along with an outlook on where the field is heading. An important theme from the series is the marked disease heterogeneity within the common classifications of T1D and T2D, and how phenotype and genotype could be better used to stratify and manage diabetes subtypes, hopefully leading to a more personalised approach that should further improve quality of life (Ahlqvist et al. 2021, Ikle \& Gloyn 2021, Martens et al. 2021, Richardson \& Pugliese 2021).

The review by Ahlqvist et al. (2021) considers the heterogeneity of common forms of diabetes, providing a timely update of the clustering method the group have developed to stratify subtypes of diabetes based on clinical variables. This includes key studies in wider populations, prevalence of complications and treatment responses. They also provide a historical narrative around the evolving classification of diabetes subtypes, with the discovery of insulin clearly underpinning the concepts of insulin deficiency and insulin sensitivity. The article by Martens et al. (2021) focuses on T1D, providing a thorough discussion of the interplay between beta cells and the immune system during disease progression. They review the heterogeneity of T1D, including age of onset, aggressiveness of autoimmunity and residual beta-cell function, and discuss recent trials of immunotherapies, articulating the need for new disease-modifying approaches and for improved biomarkers during the subclinical phase of the disease. Richardson and Pugliese (2021) present a detailed account of the pathology of the pancreas during T1D, including the organisation of tissue banks and consortia which have underpinned key studies into disease aetiology. The authors review studies demonstrating the presence and persistence of pancreatic beta cells in T1D, and varying degrees of autoimmunity, which has important implications for efforts to protect, regenerate and restore endogenous beta-cell function. A timely review of the histological evidence for inflammation, viral infection and endoplasmic reticulum (ER stress in the aetiology of T1D is also provided. Ikle and Gloyn (2021) discuss the genes and phenotypes that define monogenic forms of diabetes, including maturity-onset diabetes of the young, and neonatal diabetes, and how genetic and clinical insights have influenced treatment. They introduce the use of GWAS to identify gene variants linked to T2D and predict that increasing power of genetics studies, along with clinical metrics, will improve disease stratification and treatment for polygenic forms of diabetes. Finally, Chen and Gunton (2021) review the use of islet transplant therapy for T1D, including current barriers to islet graft survival and function, and the use of pre-clinical models. These authors conclude with a review of pathways that could be deployed to regenerate pancreatic beta cells in vivo.

The discovery of insulin has enabled many important scientific, clinical and technical advances over the past century, contributing to improvements in the management and treatment of diabetes. However, the number of people living with diabetes is at an all-time high, having recently passed half a billion (537 million worldwide; IDF 2021), with this figure projected to continue rising at an alarming rate. It is clear that new strategies to prevent or reverse the disease, focusing on maintaining a functional beta-cell mass while fostering physical activity and maintenance of healthy body weight, are urgently needed. If the current diabetes epidemic is approached with the same vigour as researchers and policymakers applied to tackle COVID-19, then in the coming decades, we may finally force diabetes rates to recede.

\section{Declaration of interest}

D L E received grant support form Eli Lilly and Company, Indianapolis, for research on new approaches to protect pancreatic beta cells in T1D.

\section{Funding}

This studydid not receive any specific grant from any funding agency in the public, commercial or not-for-profit sector.

\section{References}

Ahlqvist E, Prasad RB \& Groop L 2021 Towards improved precision and a new classification of diabetes mellitus. Journal of Endocrinology 252 R59-R71. (https://doi.org/10.1530/JOE-20-0596)

Allen FM, Stillman E \& Fitz R 1919 Total Dietary Regulation in the Treatment of Diabetes, p. 11. Monograph of the Rockerfeller Institute for Medical Research.

Banting FG \& Best CH 1922 The internal secretion of the pancreas. Journal of Laboratory and Clinical Medicine 7 55-57.

Bliss M 2007 The Discovery of Insulin. The University of Chicago Press. (SBN-10: 0195329619)

Cantley J \& Ashcroft FM 2015 Q\&A: insulin secretion and type 2 diabetes: why do beta-cells fail? BMC Biology 13 33. (https://doi.org/10.1186/ s12915-015-0140-6)

Chen J \& Gunton JE 2021 Beta-cell function and human islet transplantation: can we improve? Journal of Endocrinology 248 R99-R112. (https://doi.org/10.1530/JOE-20-0590)

Eizirik DL, Pasquali L \& Cnop M 2020 Pancreatic $\beta$-cells in type 1 and type 2 diabetes mellitus: different pathways to failure. Nature Reviews: Endocrinology 16 349-362. (https://doi.org/10.1038/s41574-020-0355-7) https://joe.bioscientifica.com https://doi.org/10.1530/JOE-21-0391 (c) 2021 Society for Endocrinology Published by Bioscientifica Ltd. Printed in Great Britain 
International Diabetes Federation 2021 IDF Diabetes Atlas10th edn. Brussels, Belgium: 2021. Available at: (https://www.diabetesatlas.org)

Ikle JM \& Gloyn AL 2021100 YEARS OF INSULIN: A brief history of diabetes genetics: insights for pancreatic beta-cell development and function. Journal of Endocrinology 250 R23-R35. (https://doi. org/10.1530/JOE-21-0067)
Martens PJ, Gysemans C \& Mathieu C 2021100 YEARS OF INSULIN: Arresting or curing type 1 diabetes: an elusive goal, but closing the gap. Journal of Endocrinology 249 T1-T11. (https://doi.org/10.1530/JOE-20-0552)

Richardson SJ \& Pugliese A 2021 Pancreas pathology in type 1 diabetes: an evolving story. Journal of Endocrinology 252 R41- R57. (https://doi. org/10.1530/JOE-21-0358)

Received in final form 11 November 2021

Accepted 23 November 2021

Accepted Manuscript published online 25 November 2021
(C) 2021 Society for Endocrinology Published by Bioscientifica Ltd.
Printed in Great Britain 